\title{
Reflexiones sobre la producción arquitectónica Premium del turismo residencial en Punta del Este, Uruguay
}

\author{
Fiorella Russo Cardozo
}

Docente

Arquitecta, Facultad de Arquitectura, Universidad ORT Uruguay. Diploma de Estudios Avanzados del Doctorado en Urbanismo y Ordenación del Territorio, Universidad de Granada, España. Beca F.P.I [Formación de Personal Investigador de la Consejería de Economía, Innovación y Ciencia de la Junta de Andalucía - Departamento de Expresión Gráfica Arquitectónica y en la Ingeniería, Área de Urbanismo y Ordenación del Territorio de la Universidad de Granada] (2010-2014). 
"El neoyorquino de alto poder económico pasa el verano boreal en los "Hamptons", una serie de pequeños pueblitos sobre la costa de Long Island con enormes y carísimas propiedades frente al mar y bahías. Quizás lo más similar a los prestigiosos Hamptons con sus magníficas residencias estivales y campos de golf y nutrida vida social sean Punta del Este y José Ignacio. Con una salvedad, y disculpen mi chauvinismo: la costa uruguaya es muy superior en todo a la costa neoyorquina"1

Arq. Carlos Ott

\section{INTRODUCCIÓN}

La siguiente investigación ${ }^{2}$ centra su atención en la realidad del Uruguay post-crisis financiera de principios de siglo XXI -año 2002-. Frente a la depresión que se vivió en ese momento en la región nos interesa el impulso que el país toma para su recuperación, lanzándose a nuevos mercados extraregionales, con el fin de reactivar la industria de la construcción y promover el desarrollo inmobiliario de nuevos productos. De cara a esta situación tres ciudades cobran relevancia en el territorio uruguayo: Montevideo, Colonia y Punta del Este. En tal contexto, Punta del Este representa uno de los vitales polos de inversión y desarrollo. La región sur del país, integrada por dichas ciudades, conforma un sector del eje metropolitano del Cono Sur ubicado sobre la costa atlántica desde Buenos Aires hasta San Pablo. Esta área es la más internacionalizada y globalizada del territorio uruguayo y ofrece un gran potencial de desarrollo futuro, exponiéndose notoriamente a grandes transformaciones, especialmente MaldonadoPunta del Este como centro dinámico y privilegiado del turismo internacional, y Colonia debido a su paulatina integración a la dinámica metropolitana de Buenos Aires así como por su alto nivel de calidad de vida.
Desde los años 70, momento en que el balneario turístico consolidó gran parte de su infraestructura edilicia -fundamentalmente residencial-, no se había vuelto a vivir tanto optimismo en cuanto al desarrollo inmobiliario y turístico en Punta del Este. Es a partir del año 2005, pasado ciertamente el letargo de la crisis, que la ciudad toma fuerza e instaura su récord histórico en cuanto a las autorizaciones otorgadas por parte de las administraciones locales para la construcción de 800.000 metros cuadrados, inversión que se valora en 500.000 .000 de dólares, procedente en su mayoría de capitales internacionales extraregionales.

Hoy en día la ciudad está expuesta a una importante alteración y renovación; bajo el eslogan "Punta del Este Internacional" la ciudad se ha lanzado con ímpetu por primera vez a "venderse" al mundo equiparándose a otros destinos de características de "primer mundo", tal como refiere el arquitecto Carlos Ott al comparar Punta del Este con los Hamptons neoyorquinos. Frente a esta situación, la voluntad de cautivar a los inversores internacionales más poderosos, la ambición de conquistar más capitales y sobre todo este tipo de negocios para la ciudad, es lo que motiva a buscar nuevos modelos residenciales capaces de satisfacer la "supuesta" demanda turístico-residencial de esta nueva clientela de altísimo poder adquisitivo.

1. OTT, Carlos. El Uruguay es un país de gente inteligente. En: MAR Y SOL. Punta del Este Internacional. Anuario 2008, p.88

2. Este artículo surge a partir de la investigación realizada durante el año 2007 y comienzos de 2008 , en el que se estudia el caso de la ciudad de Punta del Este circunscrita en el contexto de la globalización. Es preciso aclarar que a lo largo del presente trabajo se retomarán ideas y conceptos anteriormente planteados en la tesis que le da origen: RUSSO CARDOZO, Fiorella. 2008. Architectural Life-style Punta del Este. La colonización del lujo: vivir en el paraíso. Montevideo: Universidad ORT Uruguay. 
Es así que la ciudad vuelve a ser colonizada por el lujo, salvo que esta vez el lujo sobrepasa las capacidades económicas de la clase media-alta de nuestro país y la región. De este modo se da origen al concepto de "arquitectura Premium", que responderá a niveles de calidad suprema y exquisita, y que estará supeditada a las elites de mayor poder adquisitivo.

\section{Antecedentes}

Si quisiéramos precisar los límites geográficos de Punta del Este como ciudad encontramos que históricamente, y al igual que sucede en la actualidad, se la asocia a un ámbito territorial más extendido al que establecen los límites catastrales peninsulares. Se incluirían hacia el este la zona de San Rafael traspasando la Barra del arroyo Maldonado; las bahías de Maldonado y Portezuelo, Punta Ballena, Laguna del Diario, las zonas intermedias y la extensa línea costera ${ }^{3}$.

La evolución histórica de la región comprendida por Maldonado y Punta del Este está indudablemente ligada al desarrollo rioplatense, el cual se vio sensiblemente afectado por los sucesos internacionales -principalmente los económicos- que caracterizaron cada época. El desarrollo que tuvo lugar en las primeras décadas del siglo $X X$ se asocia a la extraordinaria prosperidad del Uruguay y de la Argentina respecto al resto de los países latinoamericanos. Asimismo, las inmigraciones masivas de europeos a nuestras tierras y su concentración en las ciudades, sumado al elevado nivel interno de inversión y consumo promulgaron el progreso de las clases medias que adoptaron manifiestamente las modas y costumbres europeas. De esta forma las clases altas argentinas y uruguayas comienzan a manifestar su interés por destinos próximos al mar, en zonas privilegiadas geográficamente, dejando a un lado las quintas cercanas a Montevideo donde solían veranear. En 1934, Punta del Este fue, pues, declarada zona de interés nacional para el turismo.

Con la caída del mandato del Gral. Perón en Argentina en 1955 comienza un nuevo ciclo de desarrollo del balneario, favorecido también por la aprobación de la "Ley de Propiedad Horizontal" (1946) convirtiéndose Punta del Este en un polo de crecimiento regional. "La eclosión de la construcción surge en el año 1956 por una coyuntura socioeconómica propicia a las inversiones, y la Ley de Propiedad Horizontal otorga el sustento jurídico adecuado. La península era el centro gravitacional en la época y se habían originado carencias habitacionales, de servicios y urbanísticas. Como antecedentes existían algunos hoteles en altura como el Nogaró y el Miguez que con el tiempo, se irían transformando también en propiedad horizontal"4. En principio, y siguiendo las tendencias racionalistas del pensamiento arquitectónico de la época, comienzan a construirse los primeros edificios en altura. Es a partir de la década de los 50 que su silueta comienza una importante transformación. Llegados los años 60, y muy a pesar de la profunda crisis económica que experimentó el país en esos momentos, la industria de la construcción continuó con su actividad.

La siguiente explosión transcurrió en la década de los 70 con el boom de la construcción que marcó un récord histórico en cuanto a la habilitación de metros cuadrados. Surge por primera vez en nuestras ciudades la tipología de la torre exenta, la cual ofrecería variadas posibilidades en comparación con el anterior programa de bloque o pantalla, incorporando en su basamento las novísimas galerías comerciales de Punta del Este. "Las torres típicas de este período, que modificaron totalmente el paisaje de la zona, son el síntoma más evidente de los profundos cambios

3. SANMARTíN, Lina. 1992. Punta del Este, de la infancia a la pubertad. En: Elarqa (5), p.4

4. ESTUDIO CINCO ARQUITECTOS. Sky Line: electro de un paisaje. En: Elarqa (5), p.18 


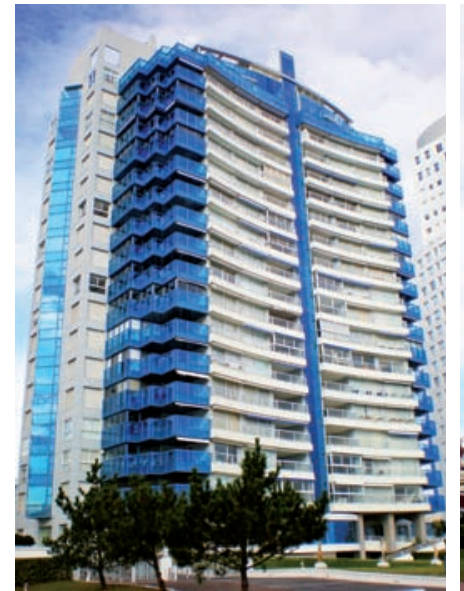

Beverly Tower

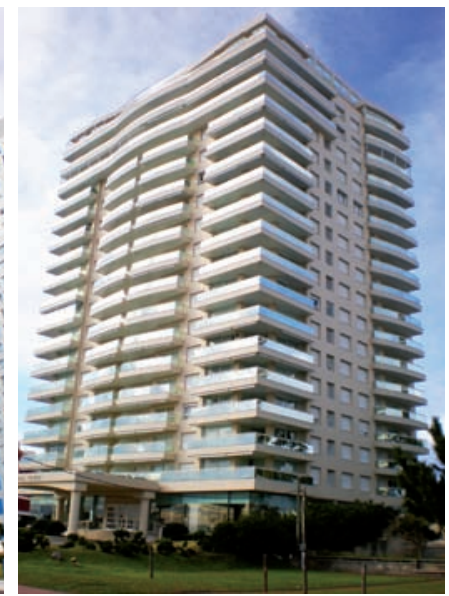

Coral Tower

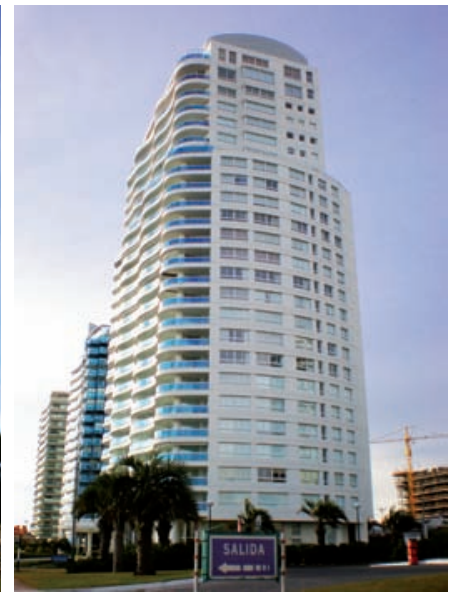

Milenium Tower

Fuente: fotografías tomadas por la autora

que se habían venido operando en la economía, en la sociedad, en la política, en el estilo de vida rioplatense: se abandona la 'Belle Époque' por la 'Sociedad del Consumo'”s

En líneas generales diremos que este boom tuvo su cese en la década de los 80 como consecuencia de una crisis económica en Argentina que luego repercute en nuestro país con una marcada devaluación de la moneda local frente a la divisa norteamericana, quedando así muchos proyectos sin concluir, cientos de personas desempleadas y provocando una importante pérdida de dinero por parte de los inversores.

Los años 90 fueron diferentes; reinó una prosperidad que se reflejó, por ejemplo, en la mejora de la calidad de vida de los habitantes. Si bien no existió un boom como en los años 70, en esta etapa se construyen los edificios más emblemáticos que dotarían a la ciudad de equipamientos a escala regional como por ejemplo el Punta Shopping, el Hotel Conrad o el aeropuerto, entre otros. La década de los 90 marcó, en especial, un antes y un después en la ciudad de Punta del Este, pese a que este bienestar sufrió un estancamiento con la entrada del nuevo siglo que consigo trajo una de las peores crisis económicas que atravesó el Uruguay, la Argentina y la región en general. En cuanto a la arquitectura residencial, en este período se construirán las torres que serán las precursoras de la arquitectura Premium que se consolidará con posterioridad a la crisis.

3. El contexto de inicios del siglo XXI y la visión transformadora de la ciudad

Primeramente, para situarnos en los motivos que dan origen a la situación actual de Punta del Este, enunciaremos que en la cuidad la crisis de comienzos del siglo XXI implicó:

a. Una nueva caída de la industria de la construcción, que durante los años 90 venía desarrollando una importante actividad a nivel nacional.

b. La deserción y ausencia de los turistas. Los uruguayos y argentinos significaban un importante porcentaje del turismo de Punta del Este y en su mayoría experimentaron dificultades financieras para tales fines.

c. La inercia de la compra-venta de inmuebles. Se estima que 3500 argentinos debieron vender sus propiedades puntaesteñas ${ }^{6}$.

d. El empobrecimiento de la ciudad. La crisis trajo

5. SANMARTÍN, Lina. op.cit. p.7

6. Cambios en la oferta de viviendas de Punta del Este. En: Propiedades (150), p.2 
Miles de metros cuadrados gestionados entre 1973 y 2007 I.M.Maldonado

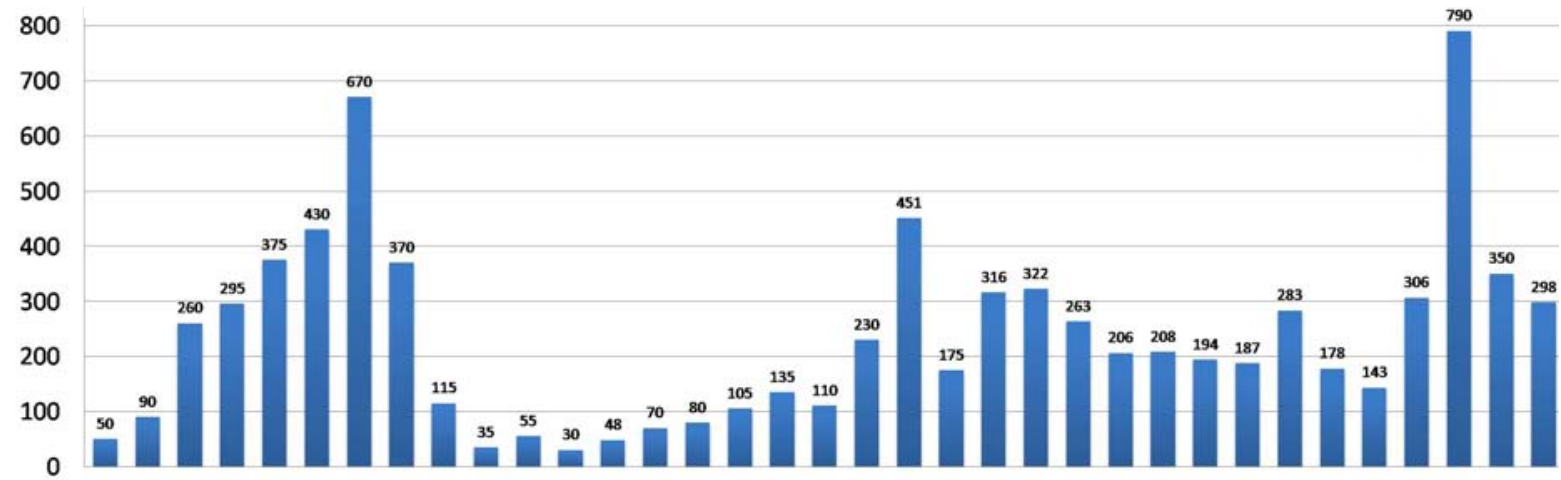

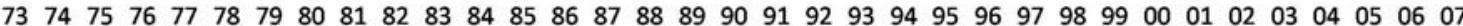

Gráfico 1: Miles de metros cuadrados gestionados en el municipio de Maldonado en el período comprendido entre 1973 y 2007

Fuente: IMMaldonado. Unidad de Coordinación de Gestión Edilicia y Suelos. Octubre de 2007

aparejado un empobrecimiento de Maldonado y de los residentes permanentes de Punta del Este. Las "malas" temporadas inducen a una disminución de ingresos para quienes hacen de Punta del Este una ciudad real, es decir sus habitantes locales.

e. Intensificación y crecimiento de las áreas marginales. Intensificación de la población en los asentamientos irregulares generando una situación social de riesgo, escenario que, además del hundimiento y trascendencia propios, implica y perjudica la imagen de la ciudad deseada y desfavorece el turismo.

Diremos que el motor que alentó a Punta del Este a su mayor internacionalización ha sido la necesidad del resurgir del aturdimiento de la crisis, observándose un aumento en las políticas de globalización que evitaran la dependencia del turismo rioplatense y los altibajos económicos de la región. Sobrepasar los límites del Río de la Plata con lleva a que Punta del Este pase a ser una ciudad más cosmopolita e internacional. "La crisis de 2001-2 del Río de la Plata generó una oportunidad única y novedosa. Por primera vez en la historia, la Argentina y el Uruguay se vieron literalmente invadidos por visitantes extrarregión. Las ventajas monetarias estimularon enérgicamente este fenómeno. Los visitantes, sorprendidos por lo cosmopolita de las ciudades de Buenos Aires y Montevideo así como por la exuberante belleza de Punta del Este, han impulsado un potente turismo en esta región. La frase infaltable al definir Punta del Este es que se encontraron con un 'paraíso perdido'. A la luz de esta situación que bien podríamos denominar 'La globalización de Punta del Este' [...] destinada a fomentar la llegada de retirados pudientes de zonas de moneda fuerte y a colaborar en la desestacionalización y a mejorar la competitividad..." 7 .

Con los intereses puestos en estimular la construcción, la administración pública a nivel departamental ${ }^{8}$ resolvió con voz y voto por parte de todas las fuerzas políticas flexibilizar los términos de tres medidas comprendidas en la ordenanza de construcción vigente que data de los años 90: el FOS -factor de ocupación del suelo-, el FOT -factor de ocupación total- y la altura.

El resultado obtenido de tal flexibilización fue un récord histórico de habilitaciones otorgadas para la construcción de 800.000 metros cuadrados en 2005 . El gráfico 1 nos permite observar cronológicamente

7. WEISS, Ricardo. Uruguay, destino Punta del Este. En: MAR Y SOL. 2007. Punta del Este Internacional: Anuario 2007. Buenos Aires: Mar y Sol Ediciones: p.13

8. Intendencia Municipal de Maldonado y la Junta Departamental de Maldonado. 


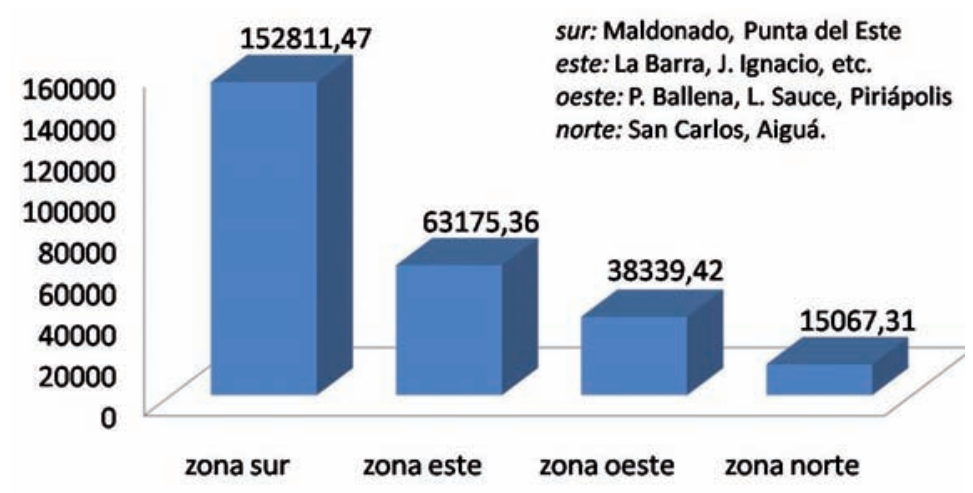

E Comportamiento total de obras autorizadas por zonas año 2007.

Gráfico 2: Comportamiento total de las obras autorizadas en el año 2007 según cada zona: sur, este, oeste y norte Fuente: IMMaldonado. Unidad de Coordinación de Gestión Edilicia y Suelos. Octubre de 2007

los vaivenes que ha experimentado la construcción en Maldonado-Punta del Este. Nos muestra que en 1979 se había habilitado la construcción de 670.000 metros cuadrados y ése era, hasta ahora, el pico más alto, seguido luego por los 450.000 metros cuadrados en 1992. Sin duda, la situación actual resulta desorbitante.

El gráfico 2 nos muestra el total de metros cuadrados gestionados en el año 2007 repartidos por zonas: en el mismo puede observarse que más del $50 \%$ de las superficies en construcción se ubican en Maldonado-Punta del Este. Esto no reproduce la cantidad de los proyectos, más bien nos da una idea de que se corresponden los metros a los tipos de emprendimiento que en la zona sur adquieren mayor densificación: las torres.

Viñoly define este auge como "una especie de multiplicación de desarrollo hormiga" que provoca una profusión de actuaciones individuales "en donde cada uno hace algo y le pone el nombre más pretencioso", perdiendo la ciudad de este modo parte del potencial que hace a sus condiciones, especialmente el paisaje y la relación con el mar.
4. El turismo residencial y el modelo global de desarrollo socio-territorial

De manera espontánea, el modelo urbano de las ciudades se va revisando y analizando en el tiempo. En este sentido, los principales cambios se verifican a través de las nuevas formas de movilidad urbana que impulsan presiones económicas, pero también como consecuencia del deseo de hallar nuevas formas de vida y de residencia inspiradas en aquello que significan socialmente, o pasan a significar.

La globalización ha encauzado un proceso evolutivo de guetos urbanos, observándose en nuestras ciudades un incremento en la creación de los mismos y una contrastada sectorización territorial. En el caso de Punta del Este, este tipo de desintegración socio-territorial se materializa en modelos lujosos concebidos tal si fueran pequeños trozos de ciudad aislados que de forma aparente se integran pero que, en definitiva, se consolidan como ciudades cerradas y no como parte indivisible de la ciudad.

El actual sentido de pertenencia que ansía el nuevo público turista hace que no resulte suficiente

9. VIÑOLY, Rafael. Un edifico no cambia la mentalidad de un lugar. En: El País [online] 20 enero de 2008 [citado 14 de marzo de 2008 ] Disponible en Internet: <http://www.elpais.com.uy/08/01/20/pciuda_325433.asp> 
una reforzada oferta de hostelería, demandando nuevos productos residenciales, cualidad que toma implicancia al momento de reflexionar respecto a este fenómeno invasivo de la ciudad contemporánea.

Punta del Este continúa siendo un destino turísticosocial de sol y playa, con una extravagante y densa vida en verano, y una relajada pasividad el resto del año, en evidente correspondencia con las características y potencialidades que el paisaje, el clima y la posición costera facilitan. No obstante, con estos programas residenciales se pretende una independización del arraigo que existe con la temporada veraniega, incrementando la oferta de una diversidad de servicios que resulten disfrutables y atractivos no sólo en verano, sino que también prolonguen las estancias, brindando un equipamiento que cubra todas las necesidades para una residencia permanente.

En líneas generales podemos considerar que Punta del Este es una ciudad nueva que tradicionalmente ha asumido la particularidad de experimentar significativos crecimientos cíclicos de forma más impulsiva que planificada; aún hoy, continúa su expansión, densificando y ampliando su oferta residencial más exclusiva. Desde esta perspectiva, si proyectamos una ligera mirada al entramado de la ciudad, instantáneamente se reconoce en su tejido la sectorización socio-espacial, que determina el derecho de admisión de quienes pueden habitar en el supuesto paraíso. Los suburbios de las elites de Punta del Este se han instalado progresivamente en lugares estratégicos, en este caso, en aquellos ubicados principalmente en primera fila sobre el mar -colonizando el paisaje costero-, así como en zonas hasta ahora identificadas por su gran valor en cuanto a naturaleza agreste.
Aunque se ratifique que el fenómeno de sectorización socio-espacial que se da en Punta del Este no es nuevo, es posible afirmar que así como sucede en grandes ciudades del mundo, también aquí se da un cambio en la magnitud y la escala que ha cobrado dicha expansión. Recordemos que Punta del Este tradicionalmente surge como recinto para el descanso veraniego de las clases sociales acomodadas locales y sobre todo de los ciudadanos argentinos, y que así sucedió durante décadas. Es recién en los años 70 que con el boom constructivo la ciudad "eleva su nivel" en forma categórica pero resulta imposible olvidar que se construyen las torres y, como consecuencia, se generaron asentamientos irregulares que nucleaban a la mano de obra utilizada en dichas torres evidenciando el comienzo de una segregación socio-territorial que progresivamente iría reafirmándose. Posteriormente, con los aportes de los años 90, la ciudad crea mayor infraestructura y pasa a tener un aeropuerto de primer nivel, un centro comercial (shopping mall), un hipermercado y un hotel cinco estrellas reconocido internacionalmente, que la posicionó en un nivel aun más elevado en su ascenso. Reconocemos que es en gran medida esta evolución la que ha viabilizado el destino que hoy presenta la ciudad.

En estos últimos años, el cambio resulta de características diferentes a los anteriores. Cambian los modelos y las escalas de los edificios, sí, pero el cambio que mayor trascendencia tiene es el nuevo escalafón de capital que económicamente se persigue. La pretensión está en parecerse más a otros destinos globales ya consolidados y de mayor envergadura -especialmente los de sol y playa como pueden ser Miami o Acapulco- y dejar de parecerse tanto a otros destinos más bien regionales de similares características a las que hasta hoy ya poseía la ciudad. 


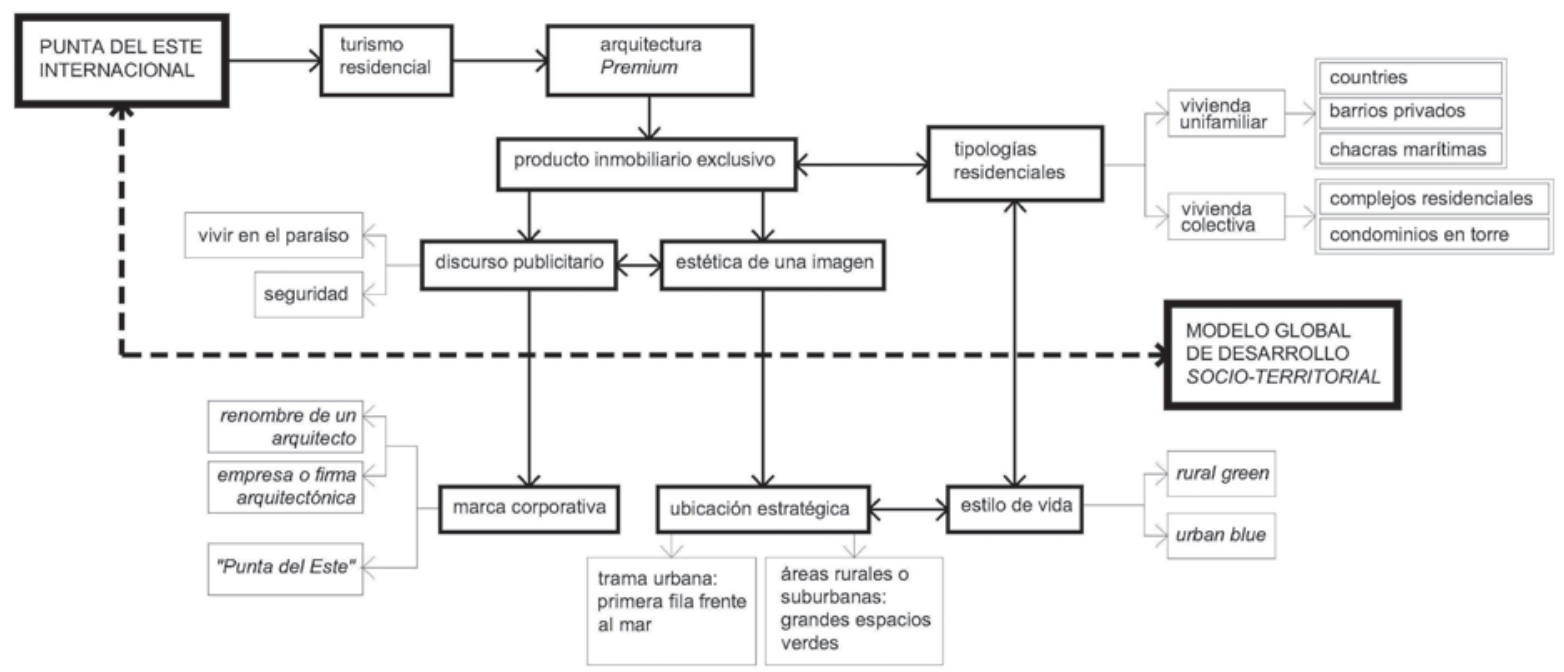

Gráfico 3: Esquema desglosado de las acciones e interacciones que se dan el proceso de transformación, partiendo del principal objetivo: consolidar a la ciudad como "Punta del Este Internacional".

Alcanzar tal ambición tiene verdaderos costos, que se pagan con la transformación de la integración entre la ciudad, su territorio y su condición social. La diferencia está en que ahora son aun mayores las distinciones sociales que coexistirán en la ciudad, por lo que la diferencia entre los nuevos consumidores y los otros se acrecienta enormemente; es necesario aclarar que los otros ${ }^{10}$ ya no son tampoco los mismos de antes.

5. La producción arquitectónica Premium y las nuevas tipologías residenciales

El concepto de arquitectura Premium se resume en la creación de un producto inmobiliario de consumo exclusivo $^{11}$ capaz de responder a la exigente clientela atraída por el turismo residencial. Esta tendencia hace que la arquitectura como recurso pase a un segundo plano de acuerdo a los siguientes factores:
- Estratégicamente el negocio Premium nos vende la estética de una imagen ideal asociada a un estilo de vida en función de las características que ofrece el emplazamiento privilegiado de los emprendimientos, que a su vez son presentados astutamente de la mano de una marca -de una firma de arquitectura o empresa constructora reconocida- o del renombre internacional de un arquitecto, como forma de potenciar la propuesta.

- Esta imagen idílica se consolida a través de un fuerte discurso publicitario que insiste en dos temas fundamentales: por un lado recurre al tópico sugestivo de vivir en el paraíso -en la ciudad deseada, y por otro se aferra al eslogan de garantizar la seguridad para una vida feliz, sosegada y sin riesgos. El gráfico 3 nos explica la integridad de este proceso, que se inicia con el objetivo de consolidar a la ciudad como "Punta del Este Internacional".

10. El término "los otros" es utilizado en representación de la ciudadanía excluida.

11. La producción arquitectónica Premium en Punta del Este es diseñada en exclusivo para el sector ABC1-el de más alto poder adquisitivo-, con la intención de atraer capitales extra-regionales; población europea y norteamericana. 
En Punta del Este, la producción arquitectónica Premium y sus modelos residenciales se definen en dos grandes categorías según el tipo de suelo en el que se ubican los emprendimientos:

1) En las áreas rurales o suburbanas -tanto hacia el lado de Punta Ballena como hacia José Ignacio- se desarrollan tres tipologías diferenciadas: los countries, los barrios privados y las chacras marítimas. Presentan una baja densidad de viviendas unifamiliares insertas en significativos predios de características paisajísticas y ambientales insuperables, rodeados de naturaleza, en los que se conjugan la práctica de deportes náuticos, golf, polo o tenis con los servicios comunes que ofrecen en su programa estas urbanizaciones: piscinas abiertas y cerradas, salas de fitness, salones de fiestas, etc.

En la promoción de estas tipologías observamos está prácticamente ausente. Imágenes y textos nos relatan el esplendor y los beneficios que ofrece vivir en ese sitio, intercalando fotografías impactantes de animales autóctonos, contrastadas con los retratos de parejas jóvenes con niños en su mayoría de aspecto nórdico -extranjeros-. Los tres modelos proponen una vida ideal en familia, en el que los niños tienen un protagonismo asociado a la tranquilidad que los padres sienten al estar a salvo en el paraíso natural, sabiendo que sus hijos pueden tomar sus propias decisiones en cuanto a cómo aprovechar su día jugando sin "restricciones" porque ambos saben que dentro del emprendimiento están a salvo. Siempre están dentro, aunque se encuentren en el lago o corriendo por el bosque; el contacto con el exterior natural que promocionan no es real como tal.

Desde un punto de vista ideológico, asociaremos a ese público con un estilo de vida color verde: rural green. Estos programas atraen a una clientela que básicamente busca huir de la ciudad; una población que se identifica con los grandes espacios abiertos al ambiente natural donde su regocijo radica en sentirse libres dentro del cercado paraíso ${ }^{12}$. Destacamos asimismo que este tipo de crecimiento va en contra de la eficiencia y sostenibilidad de la ciudad, en cuanto que resulta además, costosísimo dotarlas de infraestructura -entre otras tantas cosas-.

2) En la trama urbana de la ciudad, concentradas sobre la Playa Mansa, la Playa Brava y la Península fundamentalmente ${ }^{13}$, hallamos dos tipologías de vivienda colectiva: Ios complejos residenciales de cuatro o cinco niveles y los condominios en torre. Consecuente con su emplazamiento en el tejido urbano, su cercanía al mar y el fuerte énfasis publicitario enmarcado en "el paraíso en primera fila", definiremos la identidad de estos modelos residenciales con un estilo de vida color azul: urban blue. El gran atractivo que ofrecen son: las vistas que generan al ganar en altura, tanto para los residentes -desde el interior del edificiocomo para quienes los miran desde afuera y la gran diversidad de amenities (instalaciones, comodidades y servicios) que ofertan, facilitando la residencia de forma permanente. El estilo de vida que proyectan tiene un tinte más contemporáneo y flexible, capaz de adaptarse y alcanzar, dentro de la elite que prefiere la ciudad, un público más amplio.

En términos arquitectónicos las torres Premium representan el nuevo modelo-laboratorio de la vivienda de los bon vivant del siglo XXI; urbanísticamente incorporan un uso diferente del territorio que no siempre brinda las mejores soluciones en cuanto a la calidad del espacio resultante y el impacto que la proliferación de estos edificios ocasiona; socialmente fragmentan y excluyen introduciendo conceptos y

\footnotetext{
12. Esta libertad no es del todo real, ya que por otro lado lo que le da fuerza a este tipo de emprendimientos es que garantizan una completa seguridad, a través de controles de acceso y sistemas inteligentes.

13. También destacamos algunos proyectos ubicados en la Av. Roosevelt, y en particular la propuesta del emprendimiento "Yoo", que plantea la recuperación de uno de los edificios inacabados del boom de los años 70 - "Torre Suiza"-, para transformarlo en una lujosa obra de diseño del artista francés Philippe Starck. Conjuntamente proponen a la Av. Roosevelt como el Art District de Punta del Este.
} 
estilos de vida ajenos a nuestra realidad local, pero que se imponen con el fin de atraer nuevos capitales extranjeros y lograr un acomodado posicionamiento a nivel internacional como destino turístico. Punta del Este no es ajena a los tiempos sincrónicos de torres, y realiza un significativo aporte con una nueva generación de torres tecnológicas de altísimos costos, que compiten en diseño y en récords de altura. En la producción más reciente observamos que si bien se mantiene el objetivo de contemplar el anhelo de confort que refleje un elevado estatus, la fórmula que antes tal vez transmitía la calidad arquitectónica ahora se transfiere mayoritariamente a la imagen de un negocio inmobiliario. Los consumidores han incrementado las demandas de confort exigiendo nuevos requerimientos programáticos asociados a la vivienda; se integran los últimos avances tecnológicos disponibles y todos los nuevos espacios lúdicorecreativos que admita el edificio.

En último término diremos que las lujosas torres exceden los meros requerimientos tipológicos en cuanto a su funcionalidad, a la calidad de las terminaciones o el buen diseño arquitectónico. Estos nuevos emprendimientos deben atender otros aspectos relacionados con una lista interminable de servicios -denominados en inglés amenitiesque deberán proporcionar para alcanzar el éxito, destacándose dos temas: la diversión -ocupar el tiempo libre- y la seguridad -controles físicos e inteligentes-. Se ofrece pues una amplia gama de servicios que contemplen el relax y el entretenimiento tanto de adultos como de niños y jóvenes, como si el condominio fuese un hotel de lujo o contase con su propio club privado integrado al edificio. Algunas de las amenities que reúnen en su programa son centros ejecutivos, home theatre, salas de lectura, spas, canchas de tenis, básquetbol, pádel y fútbol, jaulas de golf y piscinas climatizadas, rincón para niños, etc. Estos servicios que hacen al edificio constituyen los argumentos publicitarios para la captación y fascinación de los consumidores. Las torres Premium fusionan las prestaciones que brinda una vivienda unifamiliar con espacios equipados para el desarrollo de actividades que sólo podríamos realizar en un club, ofreciendo además los servicios de un hotel de lujo, y mejorando la seguridad que de por sí ofrece vivir en un apartamento hallándose ahora "hípervigilados".

Observamos en la producción arquitectónica Premium dos pautas diferentes de desarrollo según la forma en que son concebidos los proyectos. Están aquéllos fundados más como un negocio inmobiliario ${ }^{14}$ -corresponden a grupos de inversores o grandes empresas de arquitectura, en cuyo desempeño los arquitectos realizan su tarea más como empresarios que como profesionales- y aquéllos en los que prima la calidad del diseño, sobrevalorado a su vez por el reconocimiento que da el renombre del arquitecto como autor del edificio. Estos emprendimientos ya de por sí cuentan con un valor agregado diferente al de los anteriores. Si bien todos los realizadores son reconocidos a nivel nacional o regional, se suele identificar a los primeros con una marca o una empresa y no con una firma de autor, como es el caso de estos edificios que llegan de la mano de exitosos arquitectos de reconocimiento internacional ${ }^{15}$.

14. Ejemplos son: la Torre Aquarela, ubicada en la Playa Mansa y Parada 18, promocionada por Invergroup. Estos desarrolladores son el grupo inversor que operaba anteriormente con la firma Pintos Risso, y debemos decir que a ellos se debe gran parte del desarrollo edilicio de Punta del Este. Otro ejemplo, y tal vez el más representativo son las nuevas torres "Quality Collection" de Atijas-Weiss. La trayectoria de esta firma en Punta del Este se remonta a la década de los años 70. Comienzan a destacarse las obras realizadas en los años 90, por ser precursoras, en gran medida, de lo que hoy son los condominios Premium. En un punto intermedio encontramos a la Torre Tressesenta de Estudio Cinco Arquitectos, en Avda. Roosevelt, Parada 5. En la producción de esta firma, si bien se hace presente cierta mercantilización, también está presente la intención profesional del arquitecto.

15. Ejemplos son : Sea \& Forest Tower en Playa Mansa y Parada 7 y Four Seasons Tower en Playa Mansa y Parada 4, del arquitecto uruguayo Carlos Ott; e Edificio Acqua del arquitecto Viñoly ubicado en Playa Brava y Parada 19. Esta obra despega de toda la producción actual de edificios Premium La calidad de su diseño y de la lógica en sí del edificio no encuentra comparación hasta el momento. Si anteponemos la obra de Ott a la de Viñoly, nos sucede lo mismo que con Estudio Cinco Arquitectos y Atijas-Weiss. En tales casos, la obra de Ott no llega al extremo formal que caracteriza a Viñoly, así como Estudio Cinco Arquitectos no alcanza el otro extremo que sería Atijas-Weiss y la banalización total de la arquitectura. 
El éxito inmobiliario de estos emprendimientos impone nuevas estrategias de marketing esenciales en las que destacamos: la elección de los nombres de los emprendimientos con su correspondiente logotipo ${ }^{16}$ -como marca registrada de calidad y distinción, a semejanza de una corporación-, la construcción de las salas de exposiciones (o showrooms), material gráfico impreso y digitalizado -infoarquitectura, folletería-, promoción de eventos sociales y de lanzamiento, marketing ferial y derrochadora publicidad mediática que incluye desde publicaciones de prensa o revistas hasta apariciones en programas de televisión, sin olvidarnos de la importancia que ha cobrado el desarrollo individual de un sitio web propio de cada proyecto.

Punta del Este es vendida al mundo como uno de los destinos más seguros de América Latina. Entonces cabe pensar que, contradiciendo esta virtud y las bondades que ofrece el lugar, las Torres Premium por todo lo antedicho resultan de una exageración y encarecimiento innecesarias, pues se verifica que responden específicamente a una voluntad de saciar necesidades adquiridas en otros sitios por el público al que se pretende conquistar.

Estas nuevas propuestas buscan por un lado adecuarse a las formas de vida actuales, y por otro aportan una nueva cultura material que impone otros hábitos y valores que modifican la idea del habitar. Parecería pues, que es un vínculo de ida y vuelta, en el que florecen nuevas tendencias arquitectónico-socioculturales -por definirlas de algún modo- vinculadas a la oscura relación que existe entre la oferta y la demanda inmobiliarias del mercado globalizado de hoy en día, dando sitio a una reinterpretación y revalorización social dentro del ámbito de la arquitectura residencial de las clases acomodadas.

\section{Otras visiones acerca de la ciudad}

Punta del Este es sin duda la ciudad que presenta mayor polarización económica y socio-cultural del Uruguay. Si bien se aprovecha del encanto de su paisaje natural como paraíso deseable, no podemos negar que la condición social de la ciudad y de sus áreas de influencia es compleja y en cierta medida alarmante, dado que en ella convergen diferentes situaciones sociales extremas consecuentes.

La población local de este sector comprendido por las ciudades de Maldonado y Punta del Este en su mayoría proviene de otros sitios, no son originarios del departamento ${ }^{17}$. Asimismo, si recapitulamos a los años más deprimidos de la crisis del año 2002, recordamos que existió una gran emigración general en el país, lo cual provocó que muchos de los oriundos abandonaran su ciudad. Si a esta situación se suma la población flotante -principalmente extranjera- que conforma el turismo de los adinerados, toda esta área resulta en una gran mezcla de identidades, culturas y estratos.

Ahora bien, recordemos también que la gran "avalancha" que emigró a Punta del Este en busca de oportunidades laborales, derivó en que en los momentos difíciles de recesión se fueran anclando, dando origen a nuevos paisajes de pobreza en la ciudad. Actualmente, una parte de "los otros" a los que hacíamos referencia, residen en las zonas de mayor prioridad social: Cerro Pelado, Cuñetti y sus inmediaciones, San Antonio 3, 4 y 5, Bambú, UTE, Maldonado Nuevo y sus proximidades, "9", Núñez, El placer, Kennedy y Las Violetas. Los hogares con carencias críticas se identifican en grandes manchas urbanas, concentradas en las áreas periféricas a la ciudad-paraíso, relativamente lejos del mar, lejos de

16. Citamos aquí un conglomerado de nombres de emprendimientos de lujo: "Ocean Tower", "Ocean Drive", "Yoo" "Aquarela Tower \& Club", "Millenium Tower", "Sea \& Forest" "Four Seasons Tower" "Imperiale Luxury Condominius" "Le Jardin Résidence" "Le Parc", "Swan Lake Forest", "Laguna Estate", "El Puertito Boating Village", "Acqua", etc. La extranjerización de los nombres -esta voluntariosa intención de bautizar a la arquitectura Premium en un idioma ajeno al nuestro, como vemos ya no sólo en inglés, sino también en italiano, francés y español-, podría atribuirse al proceso de internacionalización al que se aspira o al fenómeno histórico-cultural que sucede en las sociedades latinas con los nombres de pila de las personas como si llamarlas en otro idioma les diera mayor estatus, prestigio e cidentidad?

17. En su mayoría provienen de migraciones desde el interior del país buscando oportunidades de trabajo fundamentalmente en mano de obra y prestación de servicios. 
la belleza abrumadora que hacen al life-style Premium de Punta del Este.

En la actualidad, el Salario Mínimo Nacional -según datos del Instituto Nacional de Estadística (INE) de enero de 2009- se ubica en 4.441 pesos uruguayos. Traduciendo este dato a la economía internacional ${ }^{18}$, dicho valor representa unos 184 dólares estadounidenses y unos 145 euros. Considerando que el valor del metro cuadrado de los condominios de lujo oscila entre los 2000 y los 4000 dólares se necesitarían entre 11 y 22 salarios mínimos respectivamente para acceder a un metro cuadrado. Si tomamos en cuenta que las unidades rondan los quinientos metros cuadrados o más, una inversión de esta categoría costaría en el primer caso 5.500 salarios y en el segundo 11.000. Las cifras ilustran literalmente lo inaccesible que resultan para la ciudadanía uruguaya estos nuevos modelos residenciales. Por lo tanto concluimos que son aún muchos más los excluidos del nuevo paraíso Premium, y que las diferencias con quienes tienen mayor capacidad económica se ven ahora incrementadas significativamente.

Si tomamos en consideración los datos del INE en 2006, con respecto a la "estructura de oportunidades", en donde se estudian y comparan las necesidades básicas insatisfechas entre barrios de niveles socioeconómicos altos en contraste con los más carenciados, vemos que las diferencias entre los polos es cada vez más considerable, y lo seguirá siendo en la medida que se continúe elevando el nivel socioeconómico de las elites, y no se revierta la situación de los más vulnerables. Los datos demostraron que mientras que en Montevideo la diferencia es de 15 puntos entre Punta Gorda y Casabó, en Maldonado-Punta del Este los contrastes entre sus extremos socioeconómicos nos da una brecha de 30 puntos. Esto se traduce, por ejemplo, en que por cada niño -perteneciente a hogares con las necesidades básicas satisfechas- que decidiera abandonar la escuela, en los hogares más carenciados serían treinta niños, la totalidad de la clase $^{19}$.

La forma en que la ciudad se ha desarrollado a lo largo de los años, donde se han "hipervalorado" determinados sectores de su territorio asociados a las elites, conllevan a un modelo de ciudad que no deja de ser simulada y por tanto problemática e injusta, y lo seguirá siendo en forma incrementada hasta que no se tomen medidas en el asunto y se planifique a largo plazo la ciudad que queremos, y no la que queda en manos de los intereses de los inversionistas, que continuarán negando su integridad, beneficiándose a cambio de la exclusión de todo aquello que no resulta rentable. Como dice el Intendente de Maldonado Oscar De Los Santos, la luz amarilla está encendida, se deberá intervenir para hacer más justas las condiciones o el destino de la ciudad deparará a modelos no deseables como puede resultar una Río de Janeiro ${ }^{20}$.

Considerando la visión que el arquitecto Rafael Viñoly expone sobre la ciudad, vemos que su opinión es ambivalente: "Punta del Este está en este momento del ciclo positivo que siempre es, en realidad, negativo. Es la misma situación de fanatismo por el optimismo que no tiene demasiada justificación. O el pesimismo, que es lo mismo y que tampoco tiene demasiada justificación. Este es el momento del optimismo y se da sin ningún criterio de regulación urbanística clara, sin un proceso de consulta pública para que la gente tenga inherencia en proteger y definir qué es lo que va a pasar con este lugar en 15 o 20 años." 21

Viñoly reconoce que por un lado está bien continuar

18. Tomamos la cotización del dólar estadounidense a 24,05 y el euro a 30,5 (pesos uruguayos), correspondiente al mes de mayo de 2009.

19. Maldonado y Punta del Este, unidas y asustadas. [online] [citado enero de 2008]. Disponible en Internet: <http://www.elpais.com.uy/Suple/QuePasa/07/04/07/quepasa_273309.asp>

20. Entrevista a Oscar de los Santos. En: La República [online] 7 abril de 2007. [citado setiembre de 2007]. Disponible en Internet: <http://www.larepublica. com.uy/Ir3/larepublica/2007/04/07/politica/252613/esto-puede-volverse-rio-de-janeiro-si-no-encaramos-el-flagelo-de-la-pobreza-extrema/>

21. VIÑOLY, Rafael. op.cit. 


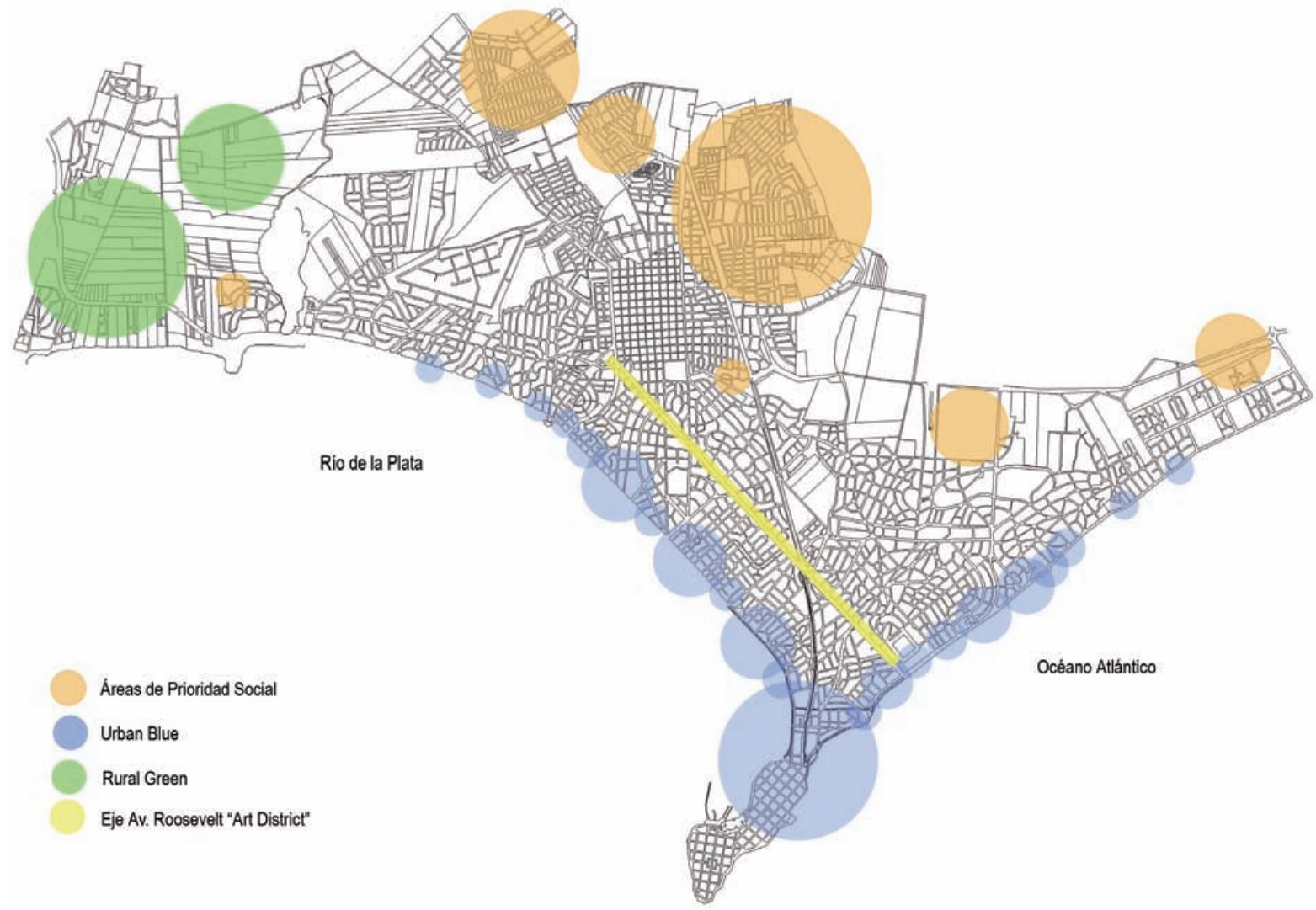

Conurbación Maldonado-Punta del Este. Representación a nivel esquemático -no exhaustivo, y generalizado- de las áreas más significativas de su territorio, en cuanto a la demanda Premium en contraste con las áreas de prioridad social. 
con el crecimiento que conduce a Punta del Este hacia el mercado mundial, pero a la vez demuestra su discrepancia frente al provenir de este crecimiento, sobre todo por la poca planificación; advierte de la necesidad de un 'planeamiento urbano y ordenación territorial' que contemple el futuro que se quiere para la ciudad; alude a que este tipo de proceso que se está experimentando responde a una visión muy a corto plazo, asociado en cierta medida a una forma de capitalismo zonzo, de un optimismo descontrolado, en donde el proceder es "entro y me voy", catalogando al ciclo como el más antiprofesional.

\section{Conclusiones}

Del proceso de desarrollo urbano que ha experimentado la ciudad, con intensos momentos de auge y sus posteriores períodos de recesión, se desprende que desde sus orígenes el balneario como polo turístico ha estado sometido a los desequilibrios socioeconómicos regionales y a las prescripciones de quienes ejercen el poder. Esto no significa que hubiesen malos propósitos, pero cabe exponer que las buenas intenciones por planificar la ciudad y encauzar de forma organizada su crecimiento no han logrado ser, hasta la actualidad, lo suficientemente contundentes como para imponerse a los diferentes intereses y estímulos que fueron tentando, y a la vez definiendo, un modo muy particular de surgir.

Quienes ejercen un rol decisivo en las políticas departamentales y por tanto en el paradigma de la ciudad, han sujetado su gestión a llevar a cabo aquellos cambios normativos necesarios y convenientes, fundamentando estas disposiciones como estratégicas, favoreciendo el modelo de ciudad deseada por quienes tienen la capacidad económica, en este caso los grandes inversores y promotores inmobiliarios. Hemos visto que estos procesos de renovación económica que hacen a los grandes cambios en la ciudad, acatan una serie de patrones de ocupación territorial que básicamente se resume en las capacidades económicas de la ciudadanía y se traducen en el territorio bajo su dualización.

Un punto importante a destacar, que demuestra el carácter global de Punta del Este -o por lo menos su anhelo-, es el lanzarse al mercado inmobiliario internacional, considerado este rubro uno de los principales negocios de la globalización. Si tomamos en consideración que la oleada constructiva viene de la mano de capitales internacionales extra-regionales, vemos que una de las formas en que se impone la globalización ante la ciudad es la de exigirle una renovación capaz de satisfacer a este nuevo público consumidor de niveles socioeconómicos muy por encima de los locales, y con culturas indiscutiblemente diferentes.

Otro indicador que hace visible la globalización en la ciudad es la adopción de los nuevos modelos residenciales importados. El sentimiento de temor generalizado es causa y consecuencia de los resultados que da la implementación de estas tipologías asociadas a las elites, entendidas como maquinarias productivas de fragmentación socio-espacial.

Respecto a la arquitectura, hemos visto que es posible definir claramente dos tendencias diferentes en cuanto a su producción, lo que dependerá fundamentalmente de la actitud del realizador. Por un lado están quienes conciben la arquitectura más como un negocio financiero, aquellos que se valen de la imagen y exaltación de la ciudad-paraíso como necesidad de amortiguar y reforzar el producto que se lanza al mercado. Se refuerza la marca de la 


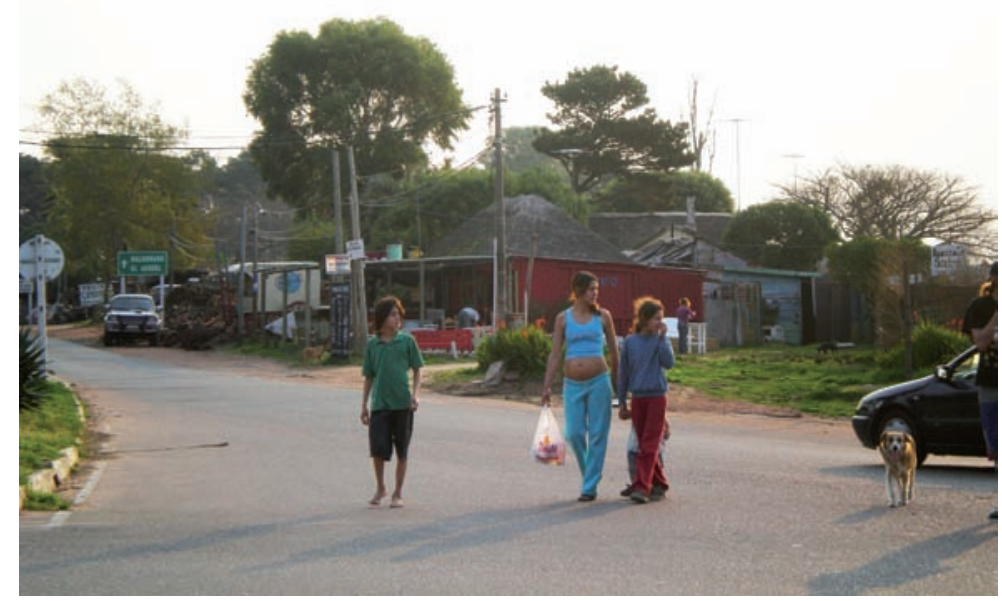

Inmediaciones del asentamiento irregular Kennedy (foto: octubre de 2007)

empresa que promociona y se refuerza y enfatiza en cuanto a la imagen de la ciudad, como antesala a la propuesta inmobiliaria. Por otro lado están aquellos profesionales de reconocimiento internacional que no necesitan narrar en su discurso la marca de la ciudad, porque incluso antes que ella está su propio prestigio.

Las construcciones que están llevándose adelante, demográficamenteimplican un incremento poblacional esporádico que deberá ser tomado en cuenta. Esta apreciación nos indica que la infraestructura y mantenimiento necesarios soporte para tales emprendimientos los tornan económicamente insostenibles, si además reflexionamos en que, de no cumplirse el gran propósito de atraer ciudadanía interesada en residir allí de forma permanente, las pretenciosas torres estarán inhabitadas, vacías, embalsamadas por más de nueve meses al año, transformando a la ciudad en un gran museo de lujo derrochado.

El caos urbano es otro de los gravísimos conflictos vinculados a los incrementos poblacionales, cuando alcanza sus picos más altos. Las principales arterias de la ciudad se ven obstaculizadas por los coches que avanzan a paso de peatón las infraestructuras de servicios, del rubro gastronomía, por ejemplo, se ven desbordadas. No sólo esto el saneamiento, el abastecimiento de agua, la recolección de residuos, todo se multiplica y la ciudad debe estar preparada para la brusquedad de estos cambios. Esta conducta estacional, si bien genera muchos puestos de trabajo durante un par de meses -lo que dura la temporada-, también evoca el consecuente desempleo al término del verano. En este sentido, la ciudad aún está muy ligada al turismo estacional. 


\section{BIBLIOGRAFÍA}

AMENDOLA, Giandomenico. 2000. La ciudad postmoderna. Madrid: Celeste.

COHE, Enrique. Los relatos del skyline. En: Elarqa (11): p. 13, oct. 1994.

Elarqa 5 (13), feb. 1995

Entrevista a Oscar de los Santos. En: La República [online] 7 abril de 2007. [citado setiembre de 2007].

Disponible en Internet: <http://www.larepublica.com.uy/Ir3/larepublica/2007/04/07/politica/252613/estopuede-volverse-rio-de-janeiro-si-no-encaramos-el-flagelo-de-la-pobreza-extrema/>

GALLARDO, Marcelo. Más torres fuera de la ordenanza en Punta del Este. En: El Espectador, [online] 10 de setiembre de 2004 [citado 23 marzo de 2007]. Disponible en Internet: http://www.espectador.com.uy/1v4_ search.php?q=m\%E1s+torres+fuera+de+la+ordenanza+en+punta+del+este

GARCÍA CANCLINI, Néstor. 1995. Consumidores y Ciudadanos: conflictos multiculturales de la globalización. México: Grijalbo.

JUNTA DEPARTAMENTAL DE MALDONADO [online] [citado enero de 2008]. Disponible en Internet: $<$ http://www.juntamaldonado.gub.uy>

Maldonado y Punta del Este, unidas y asustadas. [online] [citado enero de 2008]. Disponible en Internet: http://www.elpais.com.uy/Suple/QuePasa/07/04/07/quepasa_273309.asp

MAR Y SOL. 2007. Punta del Este Internacional: Anuario 2007. Buenos Aires: Mar y Sol Ediciones

MAR Y SOL. 2008. Punta del Este Internacional: Anuario 2008. Buenos Aires: Mar y Sol Ediciones

MUNICIPIO MALDONADO [online] [citado mayo de 2009]. Disponible en Internet:

<http://www.municipiomaldonado.gub.uy>

MUXI, Zaida. 2004. La arquitectura de la ciudad global. Barcelona: Gustavo Gili.

Propiedades (150), feb. 2000.

Revista Architector Punta del Este Real Estate (53), 2008.

RUSSO CARDOZO, Fiorella. 2008. Architectural Life-style Punta del Este. La colonización del lujo: vivir en el paraíso. Montevideo: Universidad ORT Uruguay.

SPRECHMANN, Thomas; CAPANDEGUY, Diego; AGUIAR, César. 2006. La ciudad celeste: un nuevo territorio para el Uruguay del siglo XXI. Montevideo: FArq., UdelaR, Fundación Colonia del Sacramento.

SVAMPA, Maristella. 2001. Los que ganaron: la vida en los countries y barrios privados. Buenos Aires: Biblos.

VEIGA, Danilo. Las sociedades locales en el contexto de la globalización: estudio de casos en Uruguay. En: EURE [online] 25 (74): pp.71-82, mayo 1999 [citado setiembre de 2007]. Disponible en Internet: http://www.scielo.cl/scielo.php?script=sci_arttext\&pid=S0250-71611999007400005\&lng=es\&nrm=iso\&tlng $=\mathrm{es}$

VIANA, Isabel; SIENRA, Juan Andrés; LÓPEZ, Rosario. 1992. Lineamientos generales para un Plan Director de las ciudades de Maldonado y Punta del Este. Maldonado: Intendencia Municipal de Maldonado.

VILLEGAS BERRO, Francisco. La arquitectura turística de Punta del Este. En: Arquitectura Latinoamericana. (1), 1981

VIÑOLY, Rafael. Un edifico no cambia la mentalidad de un lugar. En: El País [online] 20 enero de 2008 [citado 14 de marzo de 2008]. Disponible en Internet: http://www.elpais.com.uy/08/01/20/pciuda_325433.asp 
Cómo citar:

Russo Cardozo, F. (2020). Reflexiones sobre la producción arquitectónica Premium del turismo residencial en Punta del Este, Uruguay. Anales de Investigación en Arquitectura, 1(1), 31-48. https:// doi.org/10.18861/ania.2011.1.1.3046 